\title{
The Physiologic Effects of Surfactant Treatment on Gas Exchange in Newborn Premature Infants with Hyaline Membrane Disease
}

\author{
ROBERT B. COTTON, TORSTEN OLSSON, AMY B. LAW, ROBERT A. PARKER, \\ DANIEL P. LINDSTROM. ANTS R. SILBERBERG, HÅKAN W. SUNDELL, AND \\ KENNETH SANDBERG \\ Departments of Pediatrics and Preventive Medicine, Vanderbilt University School of Medicine. \\ Nashville. Tennessee 37232-2370 [R.B.C., A.B.L., R.A.P., D.P.L., H.W.S.J. and Department of Applied \\ Electronics. Chalmers University' of Technology: Goteborg, Sweden /T.O., A.R.S., K.S.J
}

\begin{abstract}
To describe the physiologic effects of surfactant treatment on gas exchange in human premature infants with hyaline membrane disease, functional residual capacity (FRC), tidal volume $\left(V_{T}\right)$, the alveolar portion of tidal volume $\left(\mathbf{V}_{\mathrm{A}}\right)$, alveolar ventilation $\left(\dot{V}_{A}\right)$, nitrogen clearance index, effective breath fraction calculated as $V_{A} / V_{T}$, compliance of the respiratory system, and arterial oxygen and carbon dioxide tensions were measured in 17 patients before and $0.5,2$, and $6 \mathrm{~h}$ after the administration of a single dose of either a synthetic surfactant (SS), Exosurf $(n=10)$, or a bovine surfactant (BS), Survanta $(n=7)$. By $2 \mathrm{~h}$, treatment with either BS or SS was followed by an increase in the arterial/alveolar ratio of $\mathrm{Po}_{2}(\mathrm{a} / \mathrm{A})$ and in FRC $(p<0.01$ for both a/A and FRC). The a/A and FRC improved sooner $(p<0.001)$ and to a greater extent $(p<$ 0.01 ) after BS than after SS. Compliance of the respiratory system and $V_{T}$ were decreased after either BS or SS at 0.5 $h(p<0.01)$ and remained decreased after SS at $2 h(p<$ $0.01)$. There was no significant change in $V_{A}$ or $\dot{V}_{A}$ after either BS or SS. Because FRC and a/A increased without an accompanying increase in $V_{A}, \dot{V}_{A}$, or compliance of the respiratory system, we believe that the immediate increase in FRC in this study was caused by stabilization of gas exchange units already being ventilated in addition to recruitment of new units. Nitrogen clearance index decreased and effective breath fraction increased after treatment, indicating an improved efficiency in gas mixing also thought to result from stabilization and maintenance of patency of distal airways by surfactant. (Pediatr Res 34: 495-501, 1993)
\end{abstract}

\section{Abbreviations}

HMD, hyaline membrane disease

FRC, functional residual capacity

$V_{T}$, tidal volume

$V_{A}$, alveolar portion of tidal volume

$\dot{\mathrm{V}}_{\mathrm{A}}$, alveolar ventilation

$\mathrm{NCI}$, nitrogen clearance index

EBF, effective breath fraction

$\mathrm{C}_{\mathrm{rs}}$, compliance of the respiratory system

$R_{r s}$, resistance of the respiratory system

BS, bovine surfactant (Survanta)

SS, synthetic surfactant (Exosurf)

Received December 29. 1992; accepted May 26, 1993.

Correspondence: Robert B. Cotton, M.D., Vanderbilt University Medical Center, A-0126 Medical Center North. Nashville, TN 37232-2370.

Supported by NIH Pediatric Pulmonary SCOR HL-14214. Swedish Medical Research Council Project 5703, and a grant from Burroughs Wellcome Co.

\begin{abstract}
a/A ratio, ratio of arterial to alveolar oxygen tension $\mathrm{FIO}_{2}$, fractional concentration of inspired oxygen

$\mathrm{PaO}_{2}$, arterial oxygen tension

$\mathrm{PaCO}_{2}$, arterial carbon dioxide tension
\end{abstract}

Even though surfactant treatment of premature infants with HMD has become a routine practice, many of the proposed physiologic mechanisms thought to govern the effect of surfactant on gas exchange remain either unconfirmed or inadequately characterized in the intact human newborn infant. Our understanding of physiologic responses to surfactant treatment in human infants is limited by difficulties involved in assessing pulmonary function, particularly measurements of lung volume and indices of gas mixing such as alveolar ventilation that require the accurate measurement of airway flow. To our knowledge, there are only three other reports (1-3) describing the effect of surfactant treatment on lung volume in human premature infants. Although there are more reports describing the effect of surfactant treatment on the mechanical properties of the lung in human infants (4-8), the results of those studies had to be interpreted without knowledge of change in lung volume. In this study, a whole-body plethysmograph (9) was used to measure airway flow, thereby avoiding problems associated with endotracheal tube pneumotachometry such as leak around the endotracheal tube and the added dead space of the pneumotachometer.

The purpose of this study was to describe how the effects of surfactant treatment on gas exchange are mediated by physiologic mechanisms in human premature infants with HMD. Gas exchange was expressed as the a/A ratio to reflect oxygenation and as $\mathrm{PaCO}_{2}$ to reflect ventilation. The physiologic mechanisms responsible for changes in gas exchange after surfactant were investigated by measuring $C_{r s}, R_{r s}, F R C, V_{T}, V_{A}, \dot{V}_{A}$, and two indices of the efficiency of gas mixing. A second purpose of the study was to compare the effects of a BS. Survanta, which contains surfactant-associated proteins B and C, with the effects of an SS, Exosurf, which contains no protein.

\section{MATERIALS AND METHODS}

FRC, $V_{T}, V_{A}, \dot{V}_{A}, N C l, E B F, C_{r s}, R_{r s}$, oxyhemoglobin saturation, $\mathrm{PaO}_{2}$, and $\mathrm{PACO}_{2}$ were measured before and serially after the administration of a single dose of either an SS, Exosurf, or a BS, Survanta, to 17 premature infants for treatment of HMD. Seven patients received BS and 10 received SS. Four of the first five patients enrolled were given Exosurf. In subsequent patients, surfactant selection was based on gestational age, birth weight, 
and severity of lung disease in an effort to maintain comparability between the groups in regard to these factors. The investigators were not blinded in regard to type of surfactant. Measurements were obtained from all 17 patients at approximately 0.5 and $2 \mathrm{~h}$ after surfactant treatment. Measurements were also obtained 6 $\mathrm{h}$ after treatment from six of the patients who received BS and from eight of the patients who received SS. All the patients were receiving mechanical ventilation through an indwelling endotracheal tube. All were less than $24 \mathrm{~h}$ postnatal age when the study began.

Comparability between the group of patients treated with BS and the group treated with SS in regard to severity of pulmonary insufficiency was established using an index (10) expressed as the arithmetic product of venous admixture and mean applied proximal airway pressure calculated for each arterial blood gas determination between birth and time of study. The cumulative severity of pulmonary insufficiency between birth and time of study was derived by summing individual values of this arithmetic product, which had been time averaged to take into account uneven spacing between arterial blood gas samples. The overall comparability of the two surfactant groups in regard to this index and to other characteristics is given in Table 1.

Before obtaining baseline measurements of lung function, study patients were given morphine sulfate and pancuronium bromide to suppress spontaneous respiratory effort. After muscle relaxation, ventilator settings were adjusted to achieve a pulse oximeter reading $>92 \%$ at an $\mathrm{FIO}_{2} \leq 0.8$, and $\mathrm{PaCO}_{2} \leq 5.5 \mathrm{kPa}$. Bear Cub model BP 2001 respirators (Bear Medical Systems, Inc., Riverside, CA) were used to provide time-cycled, pressurelimited intermittent mandatory ventilation with positive endexpiratory pressure. After the ventilator settings had been adjusted to accommodate for suppression of spontaneous respiratory effort, they were maintained unchanged through the measurements made $2 \mathrm{~h}$ after treatment except for adjustments in $\mathrm{FIO}_{2}$ made to maintain pulse oximetry readings between 92 and $96 \%$. Ventilator settings after the study at $2 \mathrm{~h}$ were left to the discretion of the medical staff managing the patient. Either SS, $5 \mathrm{~mL} / \mathrm{kg}$, or BS, $4 \mathrm{~mL} / \mathrm{kg}$, was given as a slow infusion (over 5$20 \mathrm{~min}$ ) into the side port of an endotracheal tube adaptor (Respiratory Support Products, Inc., Irvine, CA) without disconnecting the patient from the ventilator circuit.

Table 1. Characteristics of study patients*

\begin{tabular}{lcc}
\hline & \multicolumn{2}{c}{ Surfactant type } \\
\cline { 2 - 3 } & BS & SS \\
\hline Number & 7 & 10 \\
Male & 2 & 3 \\
Birth weight $(\mathrm{g})$ & $1278 \pm 317 \dagger$ & $1577 \pm 547$ \\
Gestational age (wk) & $29.6 \pm 1.5$ & $30.9 \pm 2.2$ \\
Age at start of study (h) & $7.4 \pm 1.7$ & $9.5 \pm 5.8$ \\
Flo & $0.66 \pm 0.14$ & $0.71 \pm 0.10$ \\
$\mathrm{PaO}_{2}$ (kPa) & $7.8 \pm 2.4$ & $7.7 \pm 2.0$ \\
$\mathrm{O}_{2}$ saturation by pulse oximeter & $95.3 \pm 2.1$ & $94.5 \pm 2.1$ \\
$\quad$ (\%) & & \\
Arterial pH & $7.38 \pm 0.03$ & $7.39 \pm 0.04$ \\
Arterial base excess (mmol/L) & $-3.9 \pm 1.5$ & $-3.3 \pm 1.3$ \\
Peak inspiratory pressure (cm & $25.0 \pm 3.8$ & $28.1 \pm 3.4$ \\
$\left.\quad \mathrm{H}_{2} \mathrm{O}\right)$ & & \\
Positive end-expiratory pressure & $4.9 \pm 0.4$ & $5.2 \pm 0.6$ \\
$\quad$ (cm $\mathrm{H}_{2} \mathrm{O}$ ) & & \\
Ventilator rate (bpm) & $12.2 \pm 2.4$ & $12.2 \pm 1.6$ \\
Mean airway pressure (cm $\left.\mathrm{H}_{2} \mathrm{O}\right)$ & & \\
Cumulative severity of pulmonary & $433 \pm 225$ & $614 \pm 436$ \\
$\quad$ insufficiency & &
\end{tabular}

* None of these characteristics were significantly different between the BS and SS groups. Values for ventilator settings and $\mathrm{FlO}_{2}$ were taken after adjustments had been made to compensate for sedation and paralysis.

$\dagger$ Mean \pm SD.
$\mathrm{PaO}_{2}$ and $\mathrm{PaCO}_{2}$ were measured from blood samples taken from an umbilical arterial catheter. Airway flow measurements used to calculate FRC, $V_{T}, V_{A}, \dot{V}_{A}, N C I, E B F, C_{r s}$, and $R_{r s}$ were obtained using the face-out whole-body plethysmographic technique described by Sjöqvist et al. (9). The technique uses a personal computer for signal analysis and data storage. The airway flow signal was derived from a differential pressure transducer (Validyne model MP45-14, Validyne Engineering Corp., Northridge, CA) and a Fleisch No. 1 pneumotachometer in the plethysmograph wall. The flow signal was compensated by the computer for the low-pass filtering influence of the plethysmograph. An airtight seal was established between the face and the cuffed face-out opening using a water-soluble gel (Aquasonic 100, Parker Laboratories Inc., Orange, NJ). Absence of leak in the system was verified by comparing the flow measured when a flow of oxygen was injected into the plethysmograph and allowed to exit through the pneumotachometer with the flow measured when the same magnitude flow of oxygen was introduced directly through the pneumotachometer. Leak was considered insignificant when the difference between these two flow measurements was less than $5 \%$. Leaks greater than $5 \%$ always could be eliminated by spreading additional gel around the margin between the cuff of the face-out port and the infant's face. If the leak were linear, a $5 \%$ leak would cause a $5 \%$ underestimate of expired $\mathrm{N}_{2}$ flow, which would cause FRC to be underestimated by $5 \%$.

$\mathrm{V}_{\mathrm{T}}$ was obtained by integration of the compensated plethysmograph flow signal over a single breath. FRC, $\dot{\mathrm{V}}_{\mathrm{A}}, \mathrm{V}_{\mathrm{A}}$, and $\mathrm{NCI}$ were measured using a multiple-breath nitrogen washout technique (11). Expired $\mathrm{N}_{2}$ concentration at the endotracheal tube adapter was measured continuously using a model 505 Nitralyzer (Med Science. Needham Heights, MA) before and after switchover during expiration to a second mechanical ventilator that delivered an $\mathrm{FIO}_{2}$ of 1.0 at settings identical to the first ventilator. The $\mathrm{N}_{2}$ concentration and flow signals were sampled at a frequency of $250 \mathrm{~Hz}$ and recorded by the computer until the washout was manually terminated when expired $\mathrm{N}_{2}$ concentration remained below $2.0 \%$. The volume of $\mathrm{N}_{2}$ expired during the washout was measured by integrating the instantaneous product of flow and $\mathrm{N}_{2}$ concentration during each expiration and inspiration.

FRC in $\mathrm{mL}$ body temperature, pressure, saturation was calculated as the volume of $\mathrm{N}_{2}$ expired during the washout divided by the difference between the end-expiratory $\mathrm{N}_{2}$ concentration before switchover and final end-expiratory $\mathrm{N}_{2}$ concentration of the washout. This method has been extensively validated in a mechanical lung and in newborn infants $(9,12)$. Based on two to six replicate measurements of FRC on 27 occasions in six infants in the Vanderbilt newborn intensive care unit, the coefficient of variation and standard error of the estimate were found to be $6.6 \%$ and $0.8 \mathrm{~mL}$, respectively. Measurements of FRC in four rabbits before and after bronchoalveolar lavage with saline documented a correlation of 0.93 between values obtained by this technique and by helium dilution over a range of $5-30 \mathrm{~mL} /$ $\mathrm{kg}$ (unpublished data).

$V_{A}$ was derived from the $N_{2}$ elimination curve, which was constructed by expressing the volume of $\mathrm{N}_{2}$ remaining in the lung after the $n$th breath of the washout, $V_{N}(n)$, as an exponential function of the breath number, $n: V_{N}(n)=V_{N}(O) \cdot w^{n} . V_{N}(O)$, the initial $\mathrm{N}_{2}$ volume in the lung, was calculated as $\mathrm{V}_{\mathrm{N}}(\mathrm{O})=$ FRC. FEN $N_{2}$, where $\mathrm{FEN}_{2}$ was the concentration of $\mathrm{N}_{2}$ in expired gas before the washout. The washout dilution factor, w, was estimated by linear regression analysis after an appropriate linear transformation. $V_{A}$ was then calculated from $w$ and FRC: $V_{A}=$ $\{(1-w) / w\} \cdot F R C$. $\dot{V}_{A}$ was calculated as the product of $V_{A}$ and the rate of mechanical ventilation in breaths per min. Additional details and theoretical considerations of this technique are documented elsewhere (11-13).

Efficiency of gas mixing was estimated by two indices, $\mathrm{NCI}$ and EBF (14). NCI was calculated as the ventilatory volume necessary to dilute the nitrogen lung volume from 90 to $10 \%$ of 
its total value, divided by the FRC $\left(n \cdot V_{T} / F R C\right)$. EBF was calculated as $\mathrm{V}_{\mathrm{A}} / \mathrm{V}_{\mathrm{T}}$.

$C_{r s}$ and $R_{r s}$ were calculated from airway pressure measured at the proximal end of the endotracheal tube and airway flow was measured from the plethysmograph as described above. Ten- to 20-s segments of these signals sampled by the computer at a frequency of $250 \mathrm{~Hz}$ were recorded for later analysis. Pressure was measured using a pressure transducer (Validyne model MP45-28-971) connected to the switchover junction between the proximal end of the endotracheal tube and the two ventilator circuits. The lengths of the rigid tubes connecting the transducers to the proximal airway and to the pneumotachometer had been adjusted to maintain the proper phase relationship between the pressure and flow signals. $C_{r s}$ and $R_{r s}$ were derived from the linear equation $P(t)=\left(1 / C_{r s}\right) \cdot \int \dot{V}(t) d t+R_{r s} \cdot \dot{V}(t)$, where $P(t)$ and $\dot{V}(t)$ are proximal airway pressure and airway flow, respectively, at time $t$. $\dot{V}(t)$ was integrated over a single breath and $C_{r s}$ and $R_{r s}$ were estimated for each individual breath using linear regression analysis. Values of $C_{r s}$ and $R_{r s}$ reported here represent averages from five to 10 breaths. A detailed description of this technique and its validation have been previously published $(12,13)$.

The study was approved by the Vanderbilt Committee for the Protection of Human Subjects. Informed consent was obtained before each patient was studied.

Statistical methods. A $t$ test was used to assess statistical significance between groups at specific time points. Difference from baseline within a group was assessed using a paired $t$ test. Similar results were found when the equivalent nonparametric tests (Wilcoxon Rank Sum Test or Wilcoxon Signed Rank Test) were used. A repeated measures analysis of variance was used to assess whether changes over time were different between the two groups. These differences were detected by the time-treatment interaction term. Significance of the association between changes in variables measured over time after surfactant treatment was assessed using regression coefficients calculated from models with the regression forced through zero. Similar conclusions were obtained when regression was performed on observed values adjusted for patient-to-patient differences.

\section{RESULTS}

Results of pulmonary function measurements made before and after surfactant treatment are summarized in Table 2 grouped according to the type of surfactant administered. There were no significant differences in the baseline values of these measurements between the group treated with BS and the group treated with SS ( $p>0.1$ for all measurements). The a/A ratio and FRC increased significantly after treatment with either BS or SS. These changes were first detected $0.5 \mathrm{~h}$ after BS treatment, but not until $2 \mathrm{~h}$ after SS treatment. The increases in FRC and a/A ratio at 0.5 and $2 \mathrm{~h}$ after treatment were significantly greater in the BS group than in the SS group. The increase in FRC remained significantly greater at $6 \mathrm{~h}$ in the BS group than the SS group, whereas the difference in a/A ratio increase between the two groups was no longer significant by this time. A significant decrease in $C_{r s}$ was detected at $0.5 \mathrm{~h}$ after treatment with either BS or SS. A significant decrease in $C_{r s}$ was still detectable $2 \mathrm{~h}$ after SS treatment. Significant decreases also were detected in $V_{T}$ after either BS or SS. The time pattern of these changes paralleled the changes in $C_{r s}$. There were significant decreases in $R_{r s} 2$ and $6 \mathrm{~h}$ after SS, but no significant change in $R_{r s}$ was observed after $\mathrm{BS}$ at any time. No significant changes in $\mathrm{PaCO}_{2}, \mathrm{~V}_{\mathrm{A}}$, or $\dot{\mathrm{V}}_{\mathrm{A}}$ were detected.

The results of measurements of gas mixing efficiency before and after surfactant treatment are shown in Table 3 . Because there were no differences in either the baseline values or the changes from baseline between the BS and SS groups $(p>0.2$ in all cases), the two groups were considered together. Both the decrease in NCI and the increase in EBF after treatment indicate an improvement in the efficiency of gas mixing.
There was a significant association between change in a/A ratio and change in FRC for both surfactants (Fig. 1). The a/A ratio increased by $0.027 \pm 0.004$ per $\mathrm{mL} / \mathrm{kg}$ increase in FRC for the SS group $(p<0.001)$ and by $0.023 \pm 0.003 \mathrm{per} \mathrm{mL} / \mathrm{kg}$ for the BS group $(p<0.001)$. There is no evidence that the change in a/A for a given change in FRC was different for the two surfactants $(p>0.4)$. $\mathrm{PaCO}_{2}$ decreased as $\dot{\mathrm{V}}_{\mathrm{A}}$ increased for both surfactants (Fig. 2). This decrease is more marked for the BS group $\left(-0.018 \pm 0.005 \mathrm{kPa}\right.$ per $\mathrm{ml} \cdot \mathrm{kg}^{-1} \cdot \mathrm{min}^{-1}$ increase, $p<$ $0.01)$ than for the SS group $(-0.006 \pm 0.003, p<0.05)$, and these two slopes are significantly different $(p<0.05)$.

\section{DISCUSSION}

Infants in this study treated with either BS or SS responded with improved oxygenation accompanied by an increase in FRC. With either surfactant, there was a significant association between the change in a/A ratio and the change in FRC. These results, which are consistent with our preliminary findings (15) and which are similar to those of Edberg et al. (1) and Goldsmith et al. (2), document the importance of FRC changes in the mechanism of improved oxygenation after surfactant treatment of infants with HMD. Based on theoretical considerations and experimental animal studies, it is likely that the increase in FRC after surfactant treatment represents either the recruitment of new gas exchange units, the stabilization of units so that they do not collapse during expiration, or a combination of both actions.

For a given volume of FRC increase, the two surfactant preparations appear to be equivalent in regard to the magnitude of improvement in oxygenation, inasmuch as the slopes of a/A ratio change as a function of FRC change were almost identical for the two groups (Fig. 1). However, the time patterns of the improvement in oxygenation and of the increase in FRC were significantly different between the two surfactants, with both a/ $A$ ratio and FRC increasing sooner and to larger values in infants receiving $B S$ than in infants receiving SS. These differences in response between BS and SS may reflect differences in physicochemical properties between the two surfactant preparations. When used to treat newborn premature rabbit pups before air breathing. SS had a less intense beneficial effect on lung mechanical properties than natural surface-active material (16). This difference was attributed to the absence of surfactant apoproteins in SS and to properties such as adsorption rate and spreading. which approach but do not equal those of purified natural lung surfactant containing trace components such as apoproteins. In the same study, no difference was observed in onset of action between SS and natural surface-active material as measured by rate of increase in $V_{T}$ during the first minute of ventilation. However, the human infants in the present study did not receive surfactant treatment until 4 to $23 \mathrm{~h}$ after birth. When surfactant is administered to premature lambs after mechanical ventilation. its distribution in the lungs is more heterogeneous than when it is administered at birth before the first breath $(17,18)$. A delay in onset of action related to physicochemical properties would possibly be exaggerated if the surfactant preparation were heterogeneously distributed in the lungs. It is also possible that the distribution of either BS or SS was influenced by the technique of instillation used in this study or the duration of the infusion.

Other factors may also contribute to the intensity and time of onset of FRC and a/A ratio responses after surfactant treatment. The biophysical activity of surfactant may be inhibited by protein leaked into airways $(19,20)$. Two factors considered to be related to the amount of protein leaked into airways by the time of study, postnatal age at surfactant treatment and cumulative severity of pulmonary insufficiency, were not statistically different between the two groups. However, the large SD of these variables and the higher mean of each variable in the SS group make it difficult to exclude completely the possible effect of these factors in this study. Also, some synthetic surfactants (although not Exosurf) have been reported to be less resistant to the 
Table 2. Effect of surfactant treatment on lung function measurements according to type of surfactant

\begin{tabular}{|c|c|c|c|c|c|c|}
\hline \multirow{2}{*}{$\begin{array}{l}\text { Lung function } \\
\text { measurement }\end{array}$} & \multirow{2}{*}{$\begin{array}{c}\text { Type of } \\
\text { surfactant }\end{array}$} & \multirow[b]{2}{*}{ Baseline* } & \multicolumn{2}{|r|}{ Change from baseline* } & \multirow[b]{2}{*}{$6.0 \mathrm{~h}$} & \multirow{2}{*}{$\begin{array}{l}\text { Significance of effect } \\
\text { of surfactant type } \\
\text { on response } \\
(p \text { value }) \dagger\end{array}$} \\
\hline & & & $0.5 \mathrm{~h}$ & $2.0 \mathrm{~h}$ & & \\
\hline \multirow[t]{2}{*}{ a/A Ratio } & BS & $0.14 \pm 0.05$ & $0.11 \pm 0.04 \ddagger \S$ & $0.10 \pm 0.04 \ddagger \S$ & $0.16 \pm 0.08 \ddagger$ & $<0.001$ \\
\hline & SS & $0.13 \pm 0.04$ & $0.01 \pm 0.05$ & $0.04 \pm 0.03 \ddagger$ & $0.12 \pm 0.06 \ddagger$ & \\
\hline \multirow[t]{2}{*}{$\mathrm{PaCO}_{2}(\mathrm{kPa})$} & BS & $4.6 \pm 0.8$ & $0.0 \pm 1.0$ & $0.0 \pm 1.3$ & $-0.3 \pm 1.4$ & NS \\
\hline & SS & $4.4 \pm 0.7$ & $0.2 \pm 0.5$ & $0.0 \pm 0.5$ & $-0.3 \pm 0.9$ & \\
\hline \multirow[t]{2}{*}{$\mathrm{FRC}(\mathrm{mL} / \mathrm{kg})$} & BS & $5.8 \pm 4.8$ & $2.7 \pm 1.8 \ddagger \$$ & $4.8 \pm 1.2 \ddagger \$$ & $6.6 \pm 2.4 \$ \$$ & $<0.001$ \\
\hline & SS & $4.2 \pm 2.3$ & $0.3 \pm 1.0$ & $1.7 \pm 1.0 \ddagger$ & $3.2 \pm 1.3 \ddagger$ & \\
\hline \multirow[t]{2}{*}{$\mathrm{C}_{\mathrm{rs}}\left(\mathrm{mL} / \mathrm{cm} \mathrm{H} \mathrm{H}_{2} \mathrm{O}\right)$} & BS & $0.327 \pm 0.088$ & $-0.070 \pm 0.039 \ddagger$ & $-0.076 \pm 0.088$ & $0.029 \pm 0.161$ & NS \\
\hline & SS & $0.408 \pm 0.146$ & $-0.068 \pm 0.050 \ddagger$ & $-0.096 \pm 0.058 \ddagger$ & $-0.023 \pm 0.084$ & \\
\hline \multirow[t]{2}{*}{$R_{r s}\left(\mathrm{~cm} \mathrm{H}_{2} \mathrm{O} \cdot \mathrm{L}^{-1} \cdot \mathrm{s}\right)$} & BS & $156 \pm 22$ & $23 \pm 104$ & $0 \pm 50$ & $-9 \pm 121$ & NS \\
\hline & SS & $182 \pm 80$ & $-21 \pm 39$ & $-42 \pm 37 \ddagger$ & $-65 \pm 49 \ddagger$ & \\
\hline \multirow[t]{2}{*}{$\mathrm{V}_{\mathrm{T}}(\mathrm{mL} / \mathrm{kg})$} & BS & $4.9 \pm 0.6$ & $-1.1 \pm 0.5 \ddagger$ & $-1.0 \pm 1.1$ & $-0.5 \pm 1.5$ & NS \\
\hline & SS & $5.5 \pm 0.9$ & $-0.9 \pm 0.5 \ddagger$ & $-1.2 \pm 0.6 \ddagger$ & $-0.6 \pm 1.0$ & \\
\hline \multirow[t]{2}{*}{$\mathrm{V}_{\mathrm{A}}(\mathrm{mL} / \mathrm{kg})$} & BS & $1.7 \pm 0.7$ & $-0.4 \pm 0.5$ & $-0.3 \pm 0.8$ & $0.0 \pm 1.0$ & NS \\
\hline & SS & $2.0 \pm 0.8$ & $-0.1 \pm 0.7$ & $-0.1 \pm 0.6$ & $0.3 \pm 0.7$ & \\
\hline \multirow[t]{2}{*}{$\dot{\mathrm{V}}_{\mathrm{A}}\left(\mathrm{mL} \cdot \mathrm{kg}^{-1} \cdot \mathrm{min}^{-1}\right)$} & BS & $96 \pm 42$ & $-24 \pm 29$ & $-20 \pm 41$ & $-16 \pm 34$ & NS \\
\hline & SS & $116 \pm 42$ & $-6 \pm 37$ & $-4 \pm 32$ & $11 \pm 49$ & \\
\hline
\end{tabular}

* Mean \pm SD.

+ Multivariate repeated measures analysis of variance was used to assess the effect of surfactant type on time pattern of response. Analysis does not include values at $6.0 \mathrm{~h}$.

$\ddagger p<0.01$ : paired $t$ test comparison with baseline value.

$\S p<0.01: t$ test comparison between BS and SS groups at this time after surfactant treatment.

Table 3. Effect of surfactant treatment on gas mixing efficiency

\begin{tabular}{ccccc}
\hline \multirow{2}{*}{$\begin{array}{c}\text { Index of } \\
\text { gas mixing }\end{array}$} & Baseline* $^{n}$ & \multicolumn{3}{c}{ Change from baseline* } \\
\cline { 2 - 5 } NCI & $9.7 \pm 4.3 \mathrm{~h}$ & $-0.10 \pm 2.8 \mathrm{~h}$ & $6.0 \mathrm{~h}$ \\
$\mathrm{EBF}$ & $0.36 \pm 0.14$ & $0.02 \pm 0.10$ & $0.05 \pm 0.11$ & $0.08 \pm 0.13^{*}$ \\
\hline
\end{tabular}

* Mean $\pm \mathrm{SD}$.

$+p<0.05$ : paired $t$ test comparison with baseline value.

inhibitory effects of plasma proteins and their derivatives than surfactants containing surfactant-associated proteins (21). In addition, birth weight, gestational age, acidosis, $\mathrm{PaO}_{2}$ immediately before treatment (22), and $\mathrm{FIO}_{2}$ at the time of treatment (23) have also been identified as risk factors for an attenuated response in oxygenation after surfactant treatment. However, the two groups of patients in this study were similar in regard to these factors.

An improvement in oxygenation and an increase in FRC do not necessarily imply the recruitment of new gas exchange units. The stabilization of gas exchange units (24) that were already being ventilated before surfactant treatment would also be ex- pected to lead to an increase in $\mathrm{FRC}$ and $\mathrm{PaO}_{2}$. During deflation, unstable alveoli collapse at their critical closing pressures. If capillary perfusion of these alveoli continues while they are collapsed, the resulting venous admixture will contribute to the overall intrapulmonary shunt and arterial hypoxemia. When unstable alveoli have been stabilized by surfactant repletion, they deflate progressively without collapse so that they retain gas volume at end-expiratory pressures below their previous critical closing pressures $(24,25)$. In stabilized alveoli, effective gas exchange with pulmonary capillary blood can take place during expiration as well as during inspiration.

The stabilization of gas exchange units already being ventilated before surfactant treatment could be one explanation for the decrease in $C_{r s}$ observed in these patients. In HMD, there is a large compartment of unventilated or poorly ventilated alveoli $(26,27)$. To attain a normal alveolar ventilation, the remaining ventilated alveoli must provide more than their normal share of $\mathrm{CO}_{2}$ transport. The smaller the ventilated compartment, the more distended will its alveoli become at end inspiration for a given tidal volume. At high volume, tissue elastance of alveolar units increases so that transpulmonary pressures in alveoli that have been distended to near maximal volume at end inspiration

\section{A. Bovine Surfactant $(n=20)$}

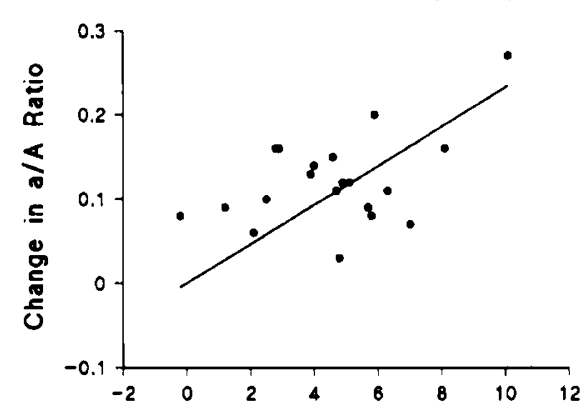

B. Synthetic Surfactant $(n=28)$

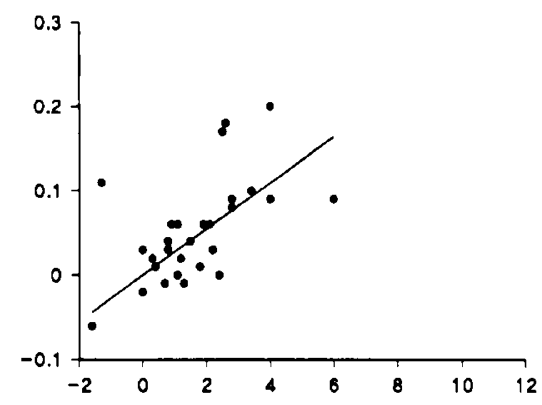

Change in FRC $(\mathrm{m} / / \mathrm{kg})$

Fig. 1. Change in a/A ratio as a function of change in FRC after treatment with either $\mathrm{BS}(A)$ or $\mathrm{SS}(B)$. The regressions through zero are shown by the solid lines. These slopes are $0.023 \pm 0.003$ for $\mathrm{BS}(p<0.001)$ and $0.027 \pm 0.004$ for $\mathrm{SS}(p<0.001)$. There is no significant difference between these two slopes $(p>0.4)$. 
A. Bovine Surfactant $(n=20)$

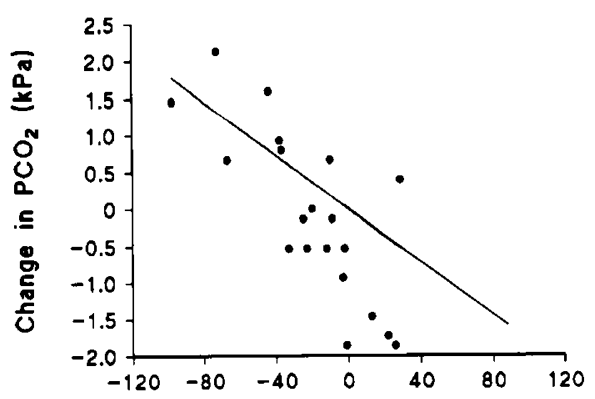

B. Synthetic Surfactant $(n=28)$

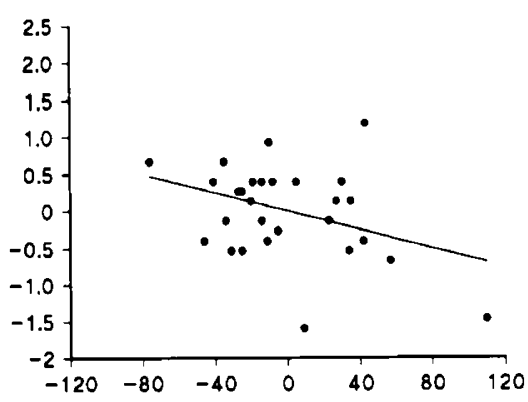

Change in $\dot{V}_{A}(\mathrm{ml} / \mathrm{min}) / \mathrm{kg}$

Fig. 2. Change in $\mathrm{PaCO}_{2}$ as a function of change in $\dot{\mathrm{V}}_{\mathrm{A}}$ after treatment with either $\mathrm{BS}(A)$ or $\mathrm{SS}(B)$. The regressions through zero are shown by the solid lines. These slopes are $-0.018 \pm 0.005$ for $\mathrm{BS}(p<0.01)$ and $-0.006 \pm 0.003$ for $\mathrm{SS}(p<0.05)$. There is a significant difference between these slopes $(p<0.05)$.

would be nearly the same in the presence or absence of surfactant $(24,28)$. Although surfactant treatment might have only little effect on the volume of these distended alveoli at end inspiration, their end-expiratory volumes would be increased by the stabilizing effect of surfactant. As a result, the volume change in these alveoli during a ventilatory cycle would decrease after surfactant treatment if ventilating pressures remained constant and if other factors such as airway resistance did not change. Consequently, $C_{r s}$ would also decrease.

This decrease in dynamic $C_{r s}$ accompanying alveolar stabilization after surfactant treatment does not imply that surfactant treatment has failed to decrease lung recoil forces. To the contrary, stabilization has occurred because the recoil force at airliquid interfaces in ventilated alveoli has been lowered by surfactant, allowing volume to be retained at an end-expiratory pressure that before surfactant treatment was insufficient to overcome the higher recoil force. $C_{r s}$, either dynamic or static, when measured over a fixed range of positive airway pressure before and after surfactant treatment, would be obtained from a pressure-volume curve that had become "flattened" after surfactant because of an elevation in volume at end expiration.

If the initial effect of surfactant treatment is limited to only those alveoli that are ventilated (either unstable or stabilized in the presence of positive end-expiratory pressure), lung compliance can only decrease when measured under the conditions described above. If the effect of surfactant treatment also includes recruitment of new terminal air spaces, lung compliance may increase, remain unchanged, or decrease, depending in part on how many alveoli have been recruited. For this reason, the results obtained in this study cannot be used to distinguish between stabilization and recruitment as mechanisms leading to the observed increase in FRC. Although not obtained in our study, static pressure-volume curves as measured in premature lambs by Vilstrup et al. (29) and in premature human infants with respiratory distress syndrome by Björklund et al. (30) would help distinguish between stabilization and simple volume recruitment.

The lack of any significant changes in $\mathrm{V}_{\mathrm{A}}, \dot{\mathrm{V}}_{\mathrm{A}}$, or $\mathrm{PaCO}_{2}$ after treatment even though $V_{T}$ decreased implies a surfactant-induced improvement in gas mixing efficiency. The changes observed in the two indices of gas mixing efficiency measured in this study, $\mathrm{EBF}$ and $\mathrm{NCI}$, also indicate improved gas mixing and are consistent with similar findings in premature lambs by Sandberg $e t$ al. (14) and by Vilstrup et al. (29), which were attributed to a stabilization of distal airways by surfactant and maintenance of patency of the peripheral airways and alveoli.

In other ways, the results in this study differ from those obtained by Sandberg et al. (14) and Vilstrup et al. (29) when premature lambs were treated with natural surfactant at or shortly after birth. Sandberg et al. (14) observed that treated lambs not only had a higher a/A ratio and FRC compared with untreated control lambs of similar gestational ages, but they also had a higher dynamic $\mathrm{C}_{\mathrm{r}}$, higher $\mathrm{V}_{\mathrm{A}}$, and lower $\mathrm{PaCO}_{2}$ than the control group. The higher dynamic $C_{r s}$ and higher $\dot{V}_{A}$ were observed at the time of the initial measurements after surfactant treatment when both the treatment group and control group were being ventilated with similar high airway pressures. In a related study, Vilstrup et al. (29) also observed that the increase in a/A ratio and FRC in newborn premature lambs after surfactant treatment at $25 \mathrm{~min}$ after birth was accompanied by an increase in both dynamic and maximum $C_{r s}$ along with an increase in $\mathrm{V}_{\mathrm{T}}$ and a decrease in $\mathrm{PaCO}_{2}$. Ventilation and dynamic $C_{r s}$ improved in their animals even though ventilator pressures were not reduced after surfactant treatment. In contrast. $\dot{\mathrm{V}}_{\mathrm{A}}$ did not change significantly and $C_{r s}$ decreased in our infants after treatment. The difference in the effect of surfactant treatment on dynamic $C_{r s}$ and ventilation between these two studies of lambs and our study of human infants may have reflected the time of surfactant administration, i.e. whether surfactant was given "prophylactically" at or shortly after birth or as a "rescue" treatment for established HMD. The effect observed in lambs given surfactant in the "prophylactic" mode is consistent with the recruitment of a larger number of open alveolar units than were attained in the control lambs. The effect observed in this study, when human infants were given surfactant in the rescue mode, is consistent with an increase in FRC caused by stabilization of units already being ventilated as well as by recruitment of new units.

The immediate increase in FRC after surfactant treatment probably involves both the stabilization of gas exchange units already being ventilated and the recruitment of new units. The relative contribution of each of these two mechanisms may depend on a large number of factors such as whether surfactant is given before or after the first breath, the degree to which terminal conducting airways are obstructed by cell slough and other products of epithelial injury (i.e. the hyaline membrane), the magnitude of end-expiratory and peak inspiratory pressures, the use of volume recruiting maneuvers such as application of sustained inflations (31) during or before surfactant administration, the effectiveness of spontaneous respiratory efforts, and the presence of other conditions that might promote or discourage alveolar recruitment. In many ways, the conditions of this study discouraged recruitment. Surfactant was given 4 to $23 \mathrm{~h}$ after birth. The patients had been given pancuronium and morphine to suppress spontaneous respiratory efforts. They were not turned and sighed as part of the surfactant administration routine. As a consequence, although some recruitment of new alveoli probably did occur, we hypothesize that the stabilization of alveoli already being ventilated contributed substantially to the FRC response observed immediately after surfactant administration with the result that $C_{r s}$ decreased and no increase in $\dot{V}_{A}$ was detected. 
Verification of this hypothesis will require additional studies of human infants with HMD and of experimental animals with surfactant deficiency.

Other studies $(1,2,4-8)$ of human infants with HMD have also shown $C_{r}$ to decrease or remain unchanged immediately after surfactant treatment. These studies were similar to ours in that surfactant was given after the diagnosis of HMD had been established rather than prophylactically, and except for one study (7), measurements of dynamic $C_{r s}$ were made from pressure and flow signals recorded during breaths provided by mechanical ventilation. When measurements were repeated from 12 to $72 \mathrm{~h}$ after surfactant administration, $\mathrm{C}_{r s}$ was observed to increase, probably as a result of ongoing alveolar recruitment and clearing of excess lung water. In some studies, an immediate increase in $C_{r}$ was measured in human infants immediately after surfactant treatment, but only when spontaneous breaths were analyzed (4), when static $C_{r s}$ was measured by a passive flow-volume technique (32), or when maximum $C_{r s}$ was obtained from recording volume and pressure change during passive, interrupted exhalation to zero pressure (30).

Interpretation of changes in lung compliance, especially dynamic $C_{r}$, after surfactant treatment must be made with caution. A wide variety of factors may influence $C_{r s}$ as measured in this and other studies. The age of the infant and prior course of ventilation, volume history of the lung, status of lung water content and distribution, pressures and rate of mechanical ventilation, the infant's spontaneous ventilatory effort, and forces resulting from the interdependence between alveolar structures are but a few of the factors that should be kept in mind when interpreting measurements of lung compliance. In addition, the physicochemical characteristics of the instilled surfactant in regard to adsorption rate and spreading, viscosity, and other properties are also important considerations. In this study, a decrease in $C_{r s}$ was detected after SS before any significant change in FRC. It is possible that the decrease in $C_{r s}$ in these patients was a consequence of the bulk presence of the exogenous liquid surfactant preparation instilled into the airways. Constriction of distal airways is known to cause a decrease in dynamic $C_{r s}(33)$. An accumulation of inadequately spread liquid surfactant in the distal airways could have a similar effect on $C_{r s}$ with either surfactant preparation. Lack of any significant change in $R_{r s}$ after $B S$ and the observed decrease in $R_{r s}$ after $S S$ do not support this explanation. However, it should be kept in mind that other factors affecting $R_{r s}$ could obscure any change in $R_{r s}$ that might result from the bulk presence of exogenous liquid surfactant in the airways.

Although there were no significant treatment effects of BS or SS on $\dot{V}_{A}$ or $\mathrm{PaCO}_{2}$, the expected association observed between $\mathrm{PaCO}_{2}$ and $\dot{\mathrm{V}}_{\mathrm{A}}$ in patients receiving $\mathrm{BS}$ was only weakly present in the SS group (Fig. 2). The implication of this finding is that changes in anatomical dead space occurring in patients treated with SS were associated with only minimal changes in physiologic dead space. The reasons for this difference between BS and SS are unclear.

Studies at $6 \mathrm{~h}$ were not obtained in two patients receiving SS and one patient receiving BS. Failure to obtain these studies was related to conflicting commitments on the part of the research personnel. The 6-h data were not essential to our final conclusions, but having these data points for 14 of the 17 study patients provided added confidence in these conclusions. Three additional patients were enrolled in this study, but their results were excluded from analysis-one because the lung disease was complicated by sepsis, another because the lung disease was complicated by progressive shock and disseminated intravascular coagulation, and the third because the age at the beginning of study was greater than $24 \mathrm{~h}$.

Our measurements of FRC, $V_{A}, \dot{V}_{A}$, and NCI were dependent on a multiple-breath $\mathrm{N}_{2}$ washout technique adapted for critically ill premature infants. A major source of error, leak around the endotracheal tube, was eliminated by using whole-body plethys- mography to measure airway flow. The technique has been extensively validated by its developers $(11-13)$. Its precision in our hands has been found to be highly acceptable.

Within $6 \mathrm{~h}$ after rescue administration, the short-term effect of surfactant treatment on gas exchange in this study of premature infants with established HMD was improved oxygenation without any significant change in ventilation. This effect was accompanied by an increase in FRC, a decrease in $C_{r s}$ and $V_{T}$, and little or no change in $\mathrm{V}_{\mathrm{A}}$ and $\dot{\mathrm{V}}_{\mathrm{A}}$. These results are consistent with a hypothesis that the increase in FRC immediately after rescue treatment with surfactant is caused by stabilization of gas exchange units already being ventilated as well as by recruitment of new units. NCI decreased and EBF increased after treatment, indicating an improved efficiency in gas mixing also thought to result from stabilization and maintenance of patency of distal airways by surfactant. Oxygenation and FRC improved sooner and to a greater extent after BS compared with SS. These differences in response may reflect differences in physicochemical properties such as adsorption rate and spreading between the two surfactant preparations.

\section{REFERENCES}

1. Edberg KE, Ekström-Jodal B. Hallman M, Hjalmarson O, Sandberg K, Silberberg A 1990 Immediate effects on lung function of instilled human surfactant in mechanically ventilated newborn infants with IRDS. Acta Paediatr Scand 79:750-755

2. Goldsmith LS. Greenspan JS, Rubenstein SD. Wolfson MR, Shaffer TH 1991 Immediate improvement in lung volume after exogenous surfactant: alveolar recruitment versus increased distention. J Pediatr 119:424-428

3. Svenningsen NW 1992 Pulmonary functional residual capacity and lung mechanics in surfactant-treated infants. Semin Perinatol 16:181-185

4. Davis JM, Veness-Meehan K. Notter RH. Bhutani VK. Kendig JW. Shapiro DL 1988 Changes in pulmonary mechanics after the administration of surfactant to infants with respiratory distress syndrome. $N$ Engl J Med 319:476-479

5. Couser RJ, Ferrara TB. Ebert J. Hoekstra RE. Fangman JJ 1990 Effects of exogenous surfactant therapy on dynamic compliance during mechanical breathing in preterm infants with hyaline membrane disease. J Pediatr 116:119-124

6. Bhat R. Dziedzic K, Bhutani VK, Vidyasagar D 1990 Effect of single dose surfactant on pulmonary function. Crit Care Med 18:590-595

7. Pfenninger J, Aebi C. Bachmann D. Wagner BP 1992 Lung mechanics and gas exchange in ventilated preterm infants during treatment of hyaline membrane disease with multiple doses of artificial surfactant (Exosurf). Pediatr Pulmonol 14:10-15

8. Bhutani VK. Abbasi S, Long WA. Gerdes JS 1992 Pulmonary mechanics and energetics in preterm infants who had respiratory distress syndrome treated with synthetic surfactant. J Pediatr 120:S18-S24

9. Sjöqvist BA. Sandberg K. Hjalmarson O, Olsson T 1984 Calculation of lung volume in newborn infants by means of a computer-assisted nitrogen washout method. Pediatr Res 18:1160-1164

10. Rojas J. Green RS. Fannon L. Olsson T. Lindstrom DP, Stahlman MT, Cotton RB 1982 A quantitative model for hyaline membrane disease. Pediatr Res 16:35-39

11. Sjöqvist BA, Sandberg K, Hjalmarson O. Olsson T 1986 Method for analysing multiple-breath nitrogen washouts. Med Biol Eng Comput 24:83-90

12. Edberg KE. Sandberg K, Silberberg A, Sjöqvist BA. Ekström-Jodal B. Hjalmarson O 1991 A plethysmographic method for assessment of lung function in mechanically ventilated very low birth weight infants. Pediatr Res 30:501504

13. Sandberg K. Sjöqvist BA. Hjalmarson O, Olsson T 1987 Lung function in newborn infants with tachypnea of unknown cause. Pediatr Res 22:581-586

14. Sandberg K. Edberg KE, Benton W. Silberberg A, Sladek M, Sundell HW 1991 Surfactant improves gas mixing and alveolar ventilation in preterm lambs. Pediatr Res 30:181-189

15. Cotton RB, Law AB. Parker RA. Lindstrom DP. Silberberg A, Sundell HW, Sandberg KR 1991 Changes in lung volume and compliance after surfactant treatment in infants with respiratory distress syndrome. Pediatr Res 29:312A(abstr).

16. Tooley WH. Clements JA, Muramatsu K, Brown CL. Schlueter MA 1987 Lung function in prematurely delivered rabbits treated with a synthetic surfactant. Am Rev Respir Dis 136:651-656

17. Jobe A, Ikegami M, Jacobs H, Jones S 1984 Surfactant and pulmonary blood flow distributions following treatment of premature lambs with natural surfactant. J Clin Invest 73:848-856

18. Walther FJ, Kuipers IM. Gidding CEM. Willebrand D, Buchholtz RTF. Bevers EM 1987 A comparison of high-frequency oscillation superimposed onto backup mechanical ventilation and conventional mechanical ventilation on the distribution of exogenous surfactant in premature lambs. Pediatr Res 22:725-729

19. Ikegami M. Jobe A, Jacobs H. Lam R 1984 A protein from airways of 
premature lambs that inhibits surfactant function. J Appl Physiol 57:11341142

20. Fuchimakai T. Fujiwara T. Takahashi A, Enhorning G 1987 Artificial pulmonary surfactant inhibited by proteins. J Appl Physiol 62:429-437

21. Holm BA, Venkitaraman AR. Enhorning G. Notter RH 1990 Biophysical inhibition of synthetic lung surfactants. Chem Phys Lipids 52:243-250

22. Blackwell M. Noguchi A. Devaskar U 1992 Factors associated with nonresponse to Surfactant TA in human neonates. Pediatr Res 31:30! A(abstr)

23. Collaborative European Multicentre Study Group 1991 Factors influencing the clinical response to surfactant replacement therapy in babies with severe respiratory distress syndrome. Eur J Pediatr 150:433-439

24. Clements JA. Hustead RF, Johnson RP, Gribetz I 1961 Pulmonary surface tension and alveolar stability. J Appl Physiol 16:444-450

25. Greaves IA. Hildebrant J. Hoppin Jr. FG 1986 Micromechanics of the lung In: Macklem PT. Mead J. Fishman AP. Geiger SR (eds) Handbook of Physiology, Section 3: The Respiratory System, Vol III. American Physiological Society, Bethesda, MD, pp 217-23i

26. Corbet AJS, Ross JA, Beaudry PH, Stern L 1974 Ventilation-perfusion relationships as assessed by aADN2 in hyaline membrane disease. J Appl Physiol 36:74-81

27. Hansen TN, Corbet AJS, Kenny JD, Courtney JD, Rudolph AJ 1979 Effects of oxygen and constant positive pressure breathing on aADCO2 in hyaline membrane disease. Pediatr Res 13:1167-1171

28. Bachofen H. Gehr P. Weibel ER 1979 Alterations of mechanical properties and morphology in excised rabbit lungs rinsed with a detergent. J Appl Physiol 47:1002-1010

29. Vilstrup C. Gommers D, Bos JAH, Lachmann B, Werner O, Larsson A 1992 Natural surfactant instilled in premature lambs increases lung volume and improves ventilation homogeneity within five minutes. Pediatr Res 32:595 599

30. Björklund LJ, Vilstrup CT, Larsson A. Werner O 1992 Pressure-volume relations and surfactant. Pediatr Res 31:301A(abstr)

31. Kolton M. Cattran CB. Kent G. Volgyesi G. Froese AB, Bryan AC 1982 Oxygenation during high-frequency ventilation compared with conventional mechanical ventilation in two models of lung injury. Anesth Analg 61:323332

32. Kelly E, Bryan H, Frndova H. Bryan C 1992 Pulmonary static compliance increases after surfactant therapy and decreased mechanical ventilation. Pediatr Res 31:312A(abstr)

33. Snapper JA, Lefferts PL 1986 Effects of aerosol histamine and carbachol on central and peripheral airflow resistance in sheep. J Appl Physiol 61:760765

\section{Announcement}

\section{Call for Abstracts}

The American Pediatric Society and The Society for Pediatric Research announce the abstract deadline for the 1994 Annual Meeting (May 2-5, 1994, Washington State Convention and Trade Center) has been set as January 4, 1994.

For further information, contact: APS/SPR Association Headquarters, 141 Northwest Point Blvd.. P.O. Box 675, Elk Grove Village, IL 60009-0675, (708) 427-0205, Fax: (708) 427-1305. 